\title{
Cytoreductive Surgery Plus Hyperthermic Intraperitoneal Chemotherapy Improves Survival in Selected Patients with Peritoneal Carcinomatosis from Abdominal and Pelvic Malignancies: Results of 21 Cases
}

\author{
Xiao-Jun Yang MD ${ }^{1}$, Yan Li MD, PhD ${ }^{1}$, Alaa Hammed al-shammaa Hassan MD ${ }^{1}$, Guo-Liang Yang MD ${ }^{1}$, \\ Shao-Yang Liu MD ${ }^{1}$, Yu-Lan Lu MD ${ }^{1}$, Jing-Wei Zhang MD ${ }^{1}$, and Yukata Yonemura MD, PhD ${ }^{2}$ \\ ${ }^{1}$ Department of Oncology, Zhongnan Hospital, Cancer Center of Wuhan University, and Hubei Cancer Clinical Study \\ Center, No. 169 Donghu Road, Wuchang District, Wuhan 430071, Hubei Province, China; ${ }^{2}$ NPO Organization to Support \\ Peritoneal Dissemination Treatment, Osaka, Japan
}

\begin{abstract}
We evaluated the perioperative safety profile and efficacy of cytoreductive surgery (CRS) plus hyperthermic intraperitoneal chemotherapy (HIPEC) in 21 patients with peritoneal carcinomatosis (PC) from gastrointestinal and gynecological cancers. Twenty-one patients with PC (12 gastric cancer, 5 colorectal cancer, 2 ovarian cancer, 1 pseudomyxoma peritonei, 1 malignant mesothelioma) were treated with CRS + HIPEC with hydroxycamptothecin $20 \mathrm{mg}$ and mitomycin C $30 \mathrm{mg}$ in $12,000 \mathrm{~mL}$ of normal saline at $43 \pm .5^{\circ} \mathrm{C}$ for 60 to 90 minutes. Vital signs were recorded for 5 days after surgery. We analyzed the following: local and systemic infections; gastrointestinal function recovery; hematological, hepatic, and renal parameters; wound healing time; adverse events; survival; and quality of life. The PC index was 2 to 33 (median, 11), the duration of operation 4 to $10 \mathrm{~h}$ (median, $8 \mathrm{~h}$ ), and the highest temperature during 5 postoperative days $38.1{ }^{\circ} \mathrm{C}$. Two patients developed generalized edema and were successfully treated. Five patients developed hypoproteinemia on day 1 after surgery. All routine blood tests checked at 1 week after surgery were normal. Time of gastric tube removal was 2 to 7 days. Liquid food intake time was 3 to 8 days. Time of removal of stitches was 8 to 18 days. No local or systemic infections, wound disruption, or other clinically important adverse events occurred. The follow-up was 8 to 43 months (median, 22.5 months). Eleven patients died, three survived with tumor, and seven survived free of
\end{abstract}

(C) The Author(s) 2008

First Received: 22 August 2008;

Published Online: 19 November 2008

Y. Li MD, PhD

e-mail: liyansd2@163.com tumor. CRS + HIPEC was well tolerated in our selected patients with PC, some of whom had improved survival.

The locoregional progression of gastrointestinal and gynecological cancers usually results in peritoneal carcinomatosis (PC), which is characterized by the presence of tumor nodules of various size, number, and distribution on the peritoneal surface, with a very poor prognosis of $<6$ months' median survival. ${ }^{1-4}$ The most widely accepted therapies for such PC are systemic chemotherapy, best support care, and palliative treatment, without any hope of cure. Moreover, surgery alone can only remove the bulky visible tumor burden. For the micrometastases, invisible free cancer cells, and those tumors not suitable for resection, surgery cannot achieve any effect. Therefore, neither surgery nor chemotherapy alone can make an obvious difference in terms of quantity and quality of life in patients with PC.

To tackle this problem, a new treatment modality called cytoreductive surgery (CRS) plus hyperthermic intraperitoneal chemotherapy (HIPEC) has been developed as novel treatment for PC. Here, we summarize the results of a phase I clinical trail conducted in our center.

\section{PATIENTS AND METHODS}

\section{Patients}

From January 2005 to January 2007, 21 patients with PC have been treated with CRS + HIPEC at the Cancer Center of Wuhan University, including 5 patients with colorectal cancer, 12 with gastric cancer, 2 with ovarian 
cancer, 1 with pseudomyxoma peritonei, and 1 with malignant mesothelioma. Major clinicopathological characteristics of the patients are listed in Table 1.

\section{$C R S+H I P E C$}

The study protocol was approved by the ethical committee of Zhongnan Hospital of Wuhan University, and all the patients provided written informed consent to participate in the study. The abdominal exploration was performed under general anesthesia and hemodynamic monitoring through a midline xiphoid-pubic incision. Once the abdominal wall was open, a detailed evaluation of the PC was conducted, taking into consideration the size and distribution of disease, according to a principle previously described. ${ }^{5}$ When the PCI evaluation was finished, maximal CRS was performed, including the resection of the primary tumor with acceptable margins, any involved adjacent structures, lymphadenectomy, and peritoneotomies where peritoneal surfaces were involved by tumor, according to previously published surgical guidelines. ${ }^{5}$

After surgery, HIPEC was performed before the closure of abdominal cavity because this open technique is believed to provide optimal thermal homogeneity and spatial diffusion, ${ }^{5,6}$ with $12 \mathrm{~L}$ of heated saline containing

TABLE 1 Clinicopathologic characteristics of 21 patients with peritoneal carcinomatosis

\begin{tabular}{ll}
\hline Characteristic & Value \\
\hline Demographic parameters & \\
$\quad$ Age range (median) (years) & $30-72(45)$ \\
Sex (M/F) & $8 / 13$ \\
Clinicopathological parameters ( $n$ ) & \\
Gastric cancer & 2 \\
$\quad$ Undifferentiated carcinoma & 4 \\
Poorly differentiated adenocarcinoma & 5 \\
Intermediately differentiated adenocarcinoma & 1 \\
Intermediately differentiated squamous cell & \\
$\quad$ carcinoma & \\
Colorectal cancer & 2 \\
$\quad$ Signet ring cell carcinoma & 2 \\
Mucous adenocarcinoma & 1 \\
Well-differentiated adenocarcinoma & \\
Ovarian cancer & 1 \\
Serous cystic adenocarcinoma & 1 \\
Serous papillary cystic adenocarcinoma & 1 \\
Pseudomyxoma peritonei & 1 \\
Malignant mesothelioma & $2-33$ \\
Peritoneal carcinomatosis index (range) & $0-3$ \\
Completeness of cytoreduction (range) & \\
\hline
\end{tabular}

$20 \mathrm{mg}$ of hydroxycamptothecin and $30 \mathrm{mg}$ of mitomycin C (MMC). An outflow tube for perfusion was placed in the Douglas pouch just before HIPEC. The perfusion solution was heated to $43.0 \pm .5^{\circ} \mathrm{C}$ in a thermostatic water bath and infused into the peritoneal cavity at a rate of $200 \mathrm{~mL} / \mathrm{min}$ through the inflow tube introduced from an automatic perfusion pump. The skin of the abdomen is attached to a retract ring, and a plastic sheet covered the open wound to keep the temperature stable. The perfusion in the peritoneal cavity was stirred manually with care not to infuse directly on the bowel surface. The first $1 \mathrm{~L}$ of perfusion solution was discarded through a drainage tube to wash out the residual debris and detached tumor cells, and the remaining solution was kept to circulate in the perfusion system. The temperature of the perfusion solution in the peritoneal space was monitored with a thermometer in real time. The total HIPEC procedure time was 60 to $90 \mathrm{~min}$. After HIPEC, the perfusion solution in the abdominal cavity was removed through the suction tube, and drainage tubes were placed at appropriate sites depending on the type of primary operation. The wound was closed with a relaxing suture, and patient was sent to the recovery room.

The extent of CRS was determined by previously published criteria on the completeness of cytoreduction (CCR). ${ }^{7,8}$ A CCR score of 0 indicates no residual peritoneal disease after CRS; 1 represents $<2.5 \mathrm{~mm}$ of residual disease; 2 indicates residual tumor between $2.5 \mathrm{~mm}$ and $2.5 \mathrm{~cm}$; and 3 indicates $>2.5 \mathrm{~cm}$ of residual tumor or the presence of a sheet of unresectable tumor nodules.

\section{Postoperative Monitoring and Follow-Up}

All patients were closely monitored for the following parameters: vital signs, bowel sound, flatus passage, drainage, and any discharges. The complete peripheral blood tests and blood chemistry were examined on the second postoperative day. Pulmonary cardiovascular functions were monitored.

Once the bowel function fully recovered, the nasogastric tube was removed, and the patient was placed on a trial liquid diet, which was gradually changed to semiliquid and soft food. The wound was examined daily, with the clinician paying particular attention to any signs of possible infection. All the information, including the time to drainage tube removal, time to suture removal, and the time on liquid food, was recorded on a special form. When patients could eat soft food and the wound suture was completely removed, they were discharged. The chemotherapy that followed was based on routine procedure.

All patients were routinely followed up by outpatient clinic or by telephone, and the information was recorded. The last time of follow-up was on August 1, 2008. 


\section{Statistical Analysis}

Data were obtained from a database of clinical records, surgical reports, medical imaging reports, laboratory and pathology reports, and follow-up records. A serious adverse event was defined as a recurrence at any site or as a disease-related death. The survival time was calculated from the date of first CRS + HIPEC to the date of patient death due to any cause. The numerical data were directly recorded, and the category data were recorded into different categories. Data were analyzed by SPSS software, version 13.0 (SPSS, Chicago, IL), with $P<.05$ considered to be statistically significant.

\section{RESULTS}

All patients underwent successful resection. The time of surgery ranged from approximately 4-10 h (median, $6 \mathrm{~h}$, mean $6 \pm 1.5 \mathrm{~h}$ ). The volume of blood loss during surgery was 500 to $3000 \mathrm{~mL}$, blood transfusion was 400 to $2200 \mathrm{~mL}$, and fluid infusion was 2000 to $6500 \mathrm{~mL}$. Eight patients received resection involving one organ part, 13 patients had resections involving more than one organ part, and 10 patients underwent partial peritonectomy greater than one quadrant of the abdomen. All patients received relaxation sutures. Ten patients transferred to the common ward after surgery, while 11 patients entered intensive care unit after surgery.

Successful wound healing was realized in all patients, and no wound infection or disruption occurred. The time to suture removal ranged from 8 to 18 days (median, 13 days), time of flatus passage from 2 to 7 days (median, 4 days), time of fluid intake from 3 to 8 days (median, 6 days), and time to drainage tubes removal from 3 to 9 days (median, 6 days). No major postoperative complications occurred, although two patients developed grade I generalized edema with puffiness of the face, arms, and legs and were treated with plasma and albumin transfusion and diuretics. The edema was relieved after 2 days.

\section{Vital Signs}

The numbers of patients with body temperature over $37^{\circ} \mathrm{C}$ were $13,10,3$, and 1 on days $1,2,3$, and 4 after surgery (Table 2). No patient experienced absorptive fever after the major operation. The hemodynamics parameters were stable, and no arrhythmia occurred.

\section{Laboratory Results}

Among the 21 patients, 3 had aspartate aminotransferase of $>46 \mathrm{U} / \mathrm{L}$ after surgery. Seven days postoperatively, only
1 patient had aspartate aminotransferase of $>46 \mathrm{U} / \mathrm{L}$. Five patients developed hypoproteinemia, but other laboratory results were normal (Table 3).

\section{Adverse Events}

No clinically important adverse events occurred in the perioperative period except for some minor abnormal laboratory results, and two patients $(9.5 \%)$ experienced edema of the face and upper extremities.

\section{Survival}

The last follow-up was on August 1, 2008, by either outpatient clinic or by telephone. The follow-up time ranged from 8 to 43 months (median, 22.5 months) for all PC patients, 29 months (range, 8-43 months) for PC patients of gastric origin, and 18 months (range, 8.5-26.5 months) for PC of colorectal origin. Eleven patients died of disease progression, one due to rectal carcinoma recurrence to ovary with 8.5-month survival, one due to rectal cancer widespread metastases to abdominal cavity with 18-month survival, one due to colon cancer widespread metastases to abdominal cavity with 15.5-month survival, one due to ovarian cancer metastases to the whole abdominal cavity with 9-month survival, one due to malignant mesothelioma metastases to the whole abdominal cavity with 30.5 -month survival, and the other six deaths due to gastric cancer progression with survivals of $8,9.5,10.5,12,15$, and 29.5 months, respectively. Three patients survived with disease, while another seven patients experienced diseasefree survival with satisfactory performance status.

The overall survival curve of 21 patients and those PC patients from gastric, colorectal, and ovarian origins are presented in Fig. 1, and detailed information for each patient is summarized in Table 4.

\section{DISCUSSION}

Neither surgery nor chemotherapy or radiotherapy alone can make any important differences in terms of quantity and quality of life in patients with PC. To tackle this difficult problem, in the 1990s, a new treatment modality called CRS + HIPEC was developed, which has the advantages of surgery to reduce the visible tumor burden and regional hyperthermic chemotherapy to eradicate micrometastases and free cancer cells. ${ }^{9}$ Since then, over 20 phase I and II studies have been conducted with promising results, and this new treatment modality has gained increasingly wide acceptance in the treatment of PC from colorectal origin at cancer centers in North America, France, Italy, German, Holland, Spain, Australia, Japan, 
TABLE 2 Important monitoring data during the 5 days after surgery

\begin{tabular}{|c|c|c|c|c|c|}
\hline \multirow[t]{2}{*}{ Index } & \multicolumn{5}{|l|}{ Range (median) } \\
\hline & Day 1 & Day 2 & Day 3 & Day 4 & Day 5 \\
\hline Temperature $\left({ }^{\circ} \mathrm{C}\right)$ & $36.7-38.1(37.3)$ & $36.7-38.0(37.3)$ & $36.2-37.2(36.8)$ & $36.3-37.2(36.8)$ & $36.1-37.1(36.7)$ \\
\hline Heart rate (bpm) & $75-117(92)$ & 75-107 (88) & 73-94 (83) & 67-94 (80) & 65-92 (82) \\
\hline
\end{tabular}

TABLE 3 Blood profile and biochemical test results

\begin{tabular}{|c|c|c|c|}
\hline \multirow[t]{2}{*}{ Parameter } & \multicolumn{2}{|l|}{ Range (median) } & \multirow[t]{2}{*}{ Normal value } \\
\hline & Day 1 & Day 7 & \\
\hline \multicolumn{4}{|l|}{ Peripheral blood test } \\
\hline Hemoglobin $(\mathrm{g} / \mathrm{L})$ & $80.6-148(118)$ & $103-136(113)$ & $120-160$ \\
\hline Red blood cell $\left(\times 10^{9} / \mathrm{L}\right)$ & $3-4.91(3.92)$ & $3.47-4.94(3.67)$ & $4-5.5$ \\
\hline White blood cell $\left(\times 10^{9} / \mathrm{L}\right)$ & $6.71-30.1(10.1)$ & $8.77-15.6(9.89)$ & $4-10$ \\
\hline Neutrophil count $\left(\times 10^{9} / \mathrm{L}\right)$ & $4.99-27.4(9.63)$ & $6.61-14.8(8.15)$ & $2-7$ \\
\hline Platelet count $\left(\times 10^{9} / \mathrm{L}\right)$ & 95.4-356 (199) & $105-336(230)$ & $100-300$ \\
\hline \multicolumn{4}{|l|}{ Liver function tests } \\
\hline Aspartate aminotransferase (U/L) & 14-99 (25) & $14-43(42)$ & $0-46$ \\
\hline Alanine aminotransferase (U/L) & $10-116(27)$ & $13-65(30)$ & $0-46$ \\
\hline $\mathrm{TB}(\mu \mathrm{mol} / \mathrm{L})$ & $.19-1.76(1.25)$ & $8.4-18.4(13.2)$ & $0-25$ \\
\hline DBILI $(\mu \mathrm{mol} / \mathrm{L})$ & $.2-12.5(3.8)$ & $1.8-6.2(5.8)$ & $0-7$ \\
\hline IBILI $(\mu \mathrm{mol} / \mathrm{L})$ & $2.9-17.9(8.8)$ & $5.5-12.56(10.3)$ & $1.5-18$ \\
\hline $\mathrm{TP}(\mathrm{g} / \mathrm{L})$ & $41.3-71(63.2)$ & $54.1-72.3(69.2)$ & $60-80$ \\
\hline $\operatorname{ALB}(g / L)$ & $26.6-45.1(24.2)$ & $30.5-42.6(40.2)$ & $35-55$ \\
\hline GLB (g/L) & $14.6-30.4(24.2)$ & $18.5-29.7(24.1)$ & $20-30$ \\
\hline Gamma glutamyl transferase $(\mathrm{g} / \mathrm{L})$ & $8-84(20)$ & $19-135(37)$ & $5-55$ \\
\hline Alkaline phosphatase (U/L) & $41-99(70)$ & $65-146(98)$ & $35-134$ \\
\hline \multicolumn{4}{|l|}{ Renal function tests } \\
\hline Blood urea nitrogen $(\mathrm{mmol} / \mathrm{L})$ & $1.69-6.68(3.27)$ & $2.9-8.92(4.08)$ & $1.7-7.2$ \\
\hline Creatine $(\mu \mathrm{mol} / \mathrm{L})$ & $47.2-103.8(59)$ & 49.3-91.2 (70.2) & $45-117$ \\
\hline \multicolumn{4}{|l|}{ Electrolytes } \\
\hline $\mathrm{K}^{+}(\mathrm{mmol} / \mathrm{L})$ & $3.68-4.9(4.2)$ & $3.08-6.52(4.22)$ & $3.5-5.5$ \\
\hline $\mathrm{Na}^{+}(\mathrm{mmol} / \mathrm{L})$ & $130-141.7(136.1)$ & $133.5-141(137.4)$ & $135-145$ \\
\hline $\mathrm{Cl}^{-}(\mathrm{mmol} / \mathrm{L})$ & $99-114.6(103.7)$ & $94.5-111.9(102.9)$ & $96-106$ \\
\hline $\mathrm{Ca}^{2+}(\mathrm{mmol} / \mathrm{L})$ & $1.81-2.9(2.25)$ & $2.18-2.4(2.26)$ & $2-2.7$ \\
\hline
\end{tabular}

$T B$ total bilirubin, $D B I L I$ direct bilirubin, $I B I L I$ indirect bilirubin, $T P$ total protein, $A L B$ albumin, $G L B$ globulin

and South Korea. ${ }^{10-13}$ After the randomized clinical trial by Netherland Cancer Center, a suggestion has been made to consider CRS and HIPEC the standard of care for patients with isolated colorectal PC. ${ }^{11,14-17}$

This phase I clinical study was performed after an animal study, which showed important benefit of intraperitoneal chemotherapy for PC. ${ }^{18}$ For the 21 patients enrolled onto this study, the perioperative safety profile was satisfactory. There were no postoperative infections and no wound disruption because we used relaxation sutures during surgery and we delayed the time of removal of stitches. The heart rates of all patients were within normal limits during the 5 days after surgery, and all patients were hemodynamically stable. The highest temperature recorded was $38.1^{\circ} \mathrm{C}$, and there was no absorption fever, which usually occurs after major abdominal surgery; the reason may be irrigation and clearance of abdominal cavity from blood residue during the HIPEC process. On the other hand, the heated chemotherapeutic agents can restrain the activity of inflammatory cells in the abdominal cavity and consequently reduce the release of cytokines, which leads to postoperative fever. Although there is no current evidence to support these hypotheses, they can be further tested in future trials. The gastrointestinal function recovery was optimal in these patients. Only two patients developed generalized edema, which might be 
FIG. 1 Overall survival curve of 21 patients with disease of gastric, colorectal, and ovarian origins

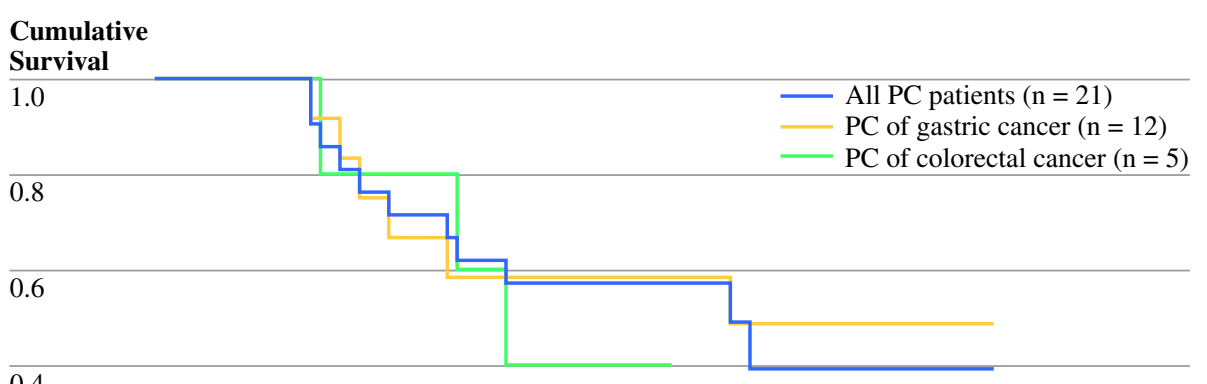

0.4

0.2

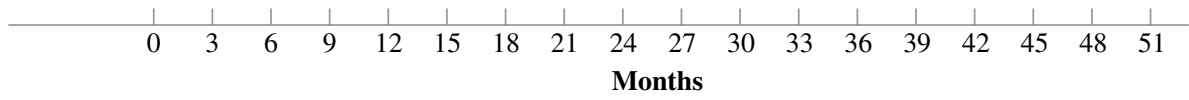

\begin{tabular}{lcccccccccccccccccc}
\hline At Risk & 21 & 21 & 21 & 18 & 15 & 13 & 12 & 12 & 12 & 12 & 10 & 10 & 10 & 10 & 10 & 10 & 10 & 10 \\
\hline Deaths & 0 & 0 & 0 & 3 & 3 & 2 & 1 & 0 & 0 & 0 & 2 & 0 & 0 & 0 & 0 & 0 & 0 & 0 \\
\hline
\end{tabular}

due to the long duration of the operations, leading to more bleeding and hypoproteinemia, but the patients were successfully treated with plasma and albumin transfusion and diuretics. There was no intestinal perforation, no anastomosis leakage, no bowel obstruction, and no intraabdominal hemorrhage or infections. These results indicate that our combined approach is a relatively safe modality of treatment with few postoperative complications.

To achieve effective cytoreduction, the field of surgery should be wide, and multiple organ parts maybe resected. ${ }^{19}$ This leads to high risks of major postoperative complications with $14 \%$ to $55 \%$ morbidity rate and $0 \%$ to $19 \%$ mortality rate, such as digestive fistulas and generalized sepsis in particular. ${ }^{20}$ In a prospective study by Yan et al. on 80 patients undergoing CRS + HIPEC for nonappendiceal PC, 1 patient died (1.3\%) on the postoperative day 22 from multiorgan failure, 11 patients (14\%) developed 12 grade I adverse events, 40 patients (50\%) developed 71 grade II adverse events, 36 patients (45\%) experienced 49 grade III adverse events, and 6 patients $(8 \%)$ experienced 8 grade IV adverse events. ${ }^{21}$ In our study, however, no serious adverse events were observed, except for grade I generalized edema in two patients $(9.5 \%)$ who were successfully treated. Such good results could be attributed to the following: (1) a fixed team of well-experienced surgeons, nursing, and operating room staff; (2) relatively mild HIPEC approach (hydroxycamptothecin, HCPT $20 \mathrm{mg}$ plus MMC $30 \mathrm{mg}$ for $60 \mathrm{~min}$ ) compared with other approach (MMC $120 \mathrm{mg} / \mathrm{m}^{2}+$ cisplatin $200 \mathrm{mg} / \mathrm{m}^{2}$ for 90 to $120 \mathrm{~min})^{20}$; (3) relaxation suture in closing abdominal wound; (4) postoperative use of effective broad-spectrum antibiotics to cover gram-positive and gram-negative aerobes and anaerobes; (5) transfusion of large-volume plasma and coagulation factors to quickly restore hypoproteinemia and stop bleeding; and (6) good nutritional support and quick restoration of electrolyte balance.

The median follow-up for the 21 patients was 22.5 months. The 1-year survival rate among all the patients was $66.7 \%$. Among the 11 patients who died, the CCR scores were 3 in seven patients, 2 in two patients, 1 in one patient, and 0 in one patient, suggesting a close correlation between CCR and survival. The CCR is the most important prognostic indicator for survival. ${ }^{10,14,22,23}$ The patients with optimal CRS followed by HIPEC showed the best 5 -year survival rate of $30 \%$, whereas those underwent incomplete CRS gained little benefit, with a median survival comparable to that reported in historical controls. ${ }^{24} \mathrm{In}$ a study by Cavaliere et al., patients with a CCR score of 0 had far higher 3-year survival rates than those with CCR scores of 1 and 2 (the $P<.001$ ). ${ }^{25}$ In 2004, Glehen et al. published a large-scale multicentric prospective study involving 506 patients who underwent CRS + HIPEC from 28 centers. The average follow-up was 53 months; the mean survival time was 19.2 months; and the 1,3 , and 5 -year survival rates were $72 \%, 39 \%$, and $19 \%$, respectively. Thirty-eight patients survived for $>5$ years. ${ }^{26}$ In 2005, Netherland Cancer Research center summarized phase I, II, and III clinical studies and analyzed the longterm cure effects of 117 patients receiving CRS + HIPEC. The median survival time was 21.8 months, and the 1-, 3-, and 5-year survival rates were $75 \%, 28 \%$, and $9 \%$, respectively. Fifty-nine patients received complete cytoreduction; median survival time was 42.9 months, and 1-, 3-, and 5-year survival rates were 94\%, 56\%, and $43 \%$, respectively. ${ }^{22}$

Despite CRS, the disease recurrence rate is still high, leading to treatment failure. In a multi-institutional study by Glehen et al., the overall incidence of recurrence was 
TABLE 4 Clinical and pathological features of 21 patients undergoing cytoreductive surgery (CRS) plus hyperthermic intraperitoneal chemotherapy (HIPEC) $)^{\mathrm{a}}$

\begin{tabular}{|c|c|c|c|c|c|c|c|}
\hline $\begin{array}{l}\text { Patient } \\
\text { no. }\end{array}$ & $\begin{array}{l}\text { Age } \\
\text { (years) }\end{array}$ & Sex & Diagnosis & PCI & Operation (CRS + HIPEC) & $\mathrm{CCR}^{\mathrm{b}}$ & $\begin{array}{l}\text { Survival } \\
\text { status }\end{array}$ \\
\hline 1 & 72 & $\mathrm{~F}$ & Krukenberg tumor & 12 & $\begin{array}{l}\text { Uterus ovary, pelvic peritoneum, fossa iliaca peritoneum visceral } \\
\text { resection. }\end{array}$ & 3 & $29.5 \mathrm{mo}$ \\
\hline 2 & 45 & $\mathrm{~F}$ & Rectal cancer & 11 & Rectum cancer resection, part pelvic peritoneum resection & 1 & $18 \mathrm{mo}$ \\
\hline 3 & 46 & $\mathrm{~F}$ & Krukenberg tumor & 5 & $\begin{array}{l}\text { Subtotal gastrectomy, ovariectomy, epigastric peritoneum visceral } \\
\text { resection }\end{array}$ & 0 & SWOT \\
\hline 4 & 50 & M & Gastric cancer & 2 & $\begin{array}{l}\text { Subtotal gastrectomy, resection of part left upper quadrant of the abdomen } \\
\text { peritoneum }\end{array}$ & 0 & SWOT \\
\hline 5 & 30 & M & Gastric cancer & 13 & $\begin{array}{l}\text { Total gastrectomy, splenectomy, partial pancreatectomy, resection of left } \\
\text { upper quadrant of the abdomen peritoneum }\end{array}$ & 3 & $8 \mathrm{mo}$ \\
\hline 6 & 70 & M & Gastric cancer & 4 & Subtotal gastrectomy, peritonectomy on the left upper quadrant & 0 & $10.5 \mathrm{mo}$ \\
\hline 7 & 37 & $\mathrm{~F}$ & Colon cancer & 26 & $\begin{array}{l}\text { Right semicolectomy, jejunum and mesenterium tumor resection, lower } \\
\text { abdominal and pelvic peritoneum resection }\end{array}$ & 2 & SWT \\
\hline 8 & 36 & $\mathrm{~F}$ & $\begin{array}{l}\text { Rectal cancer } \\
\text { recurrence in } \\
\text { ovary }\end{array}$ & 14 & $\begin{array}{l}\text { Rectum cancer resection, adnexa uteri resection, pelvic peritoneum } \\
\text { resection, part bladder resection }\end{array}$ & 3 & $8.5 \mathrm{mo}$ \\
\hline 9 & 69 & M & Gastric cancer & 2 & Subtotal gastrectomy, peritonectomy on upper left quadrant & 0 & SWOT \\
\hline 10 & 54 & $\mathrm{~F}$ & Gastric cancer & 2 & $\begin{array}{l}\text { Gastric cancer resection, part upper quadrant of the abdomen peritoneum } \\
\text { resection }\end{array}$ & 0 & SWOT \\
\hline 11 & 36 & M & Colon cancer & 6 & $\begin{array}{l}\text { Descending colon cancer resection, right lower quadrant of peritoneum } \\
\text { resection }\end{array}$ & 0 & SWOT \\
\hline 12 & 67 & $\mathrm{~F}$ & Gastric cancer & 6 & $\begin{array}{l}\text { Gastric cancer resection, left upper quadrant of the abdomen peritoneum } \\
\text { resection }\end{array}$ & 0 & $15 \mathrm{mo}$ \\
\hline 13 & 43 & M & $\begin{array}{l}\text { Remnant gastric } \\
\text { cancer }\end{array}$ & 18 & $\begin{array}{l}\text { Remnant gastric cancer resection, spleen and cauda pancreatic resection, } \\
\text { left upper quadrant of the abdomen peritoneum resection }\end{array}$ & 3 & $9.5 \mathrm{mo}$ \\
\hline 14 & 40 & M & Gastric cancer & 9 & $\begin{array}{l}\text { Total gastrectomy, left upper quadrant of the abdomen peritoneum } \\
\text { resection }\end{array}$ & 2 & $12 \mathrm{mo}$ \\
\hline 15 & 38 & $\mathrm{~F}$ & Colon cancer & 13 & $\begin{array}{l}\text { Ascending colon resection, right quadrant of peritoneum, and pelvic } \\
\text { peritoneum resection }\end{array}$ & 3 & $15.5 \mathrm{mo}$ \\
\hline 16 & 69 & M & Gastric cancer & 2 & Subtotal gastrectomy, left upper quadrant peritonectomy & 0 & SWOT \\
\hline 17 & 41 & $\mathrm{~F}$ & Gastric cancer & 2 & Subtotal gastrectomy, left upper quadrant peritonectomy & 0 & SWOT \\
\hline 18 & 59 & $\mathrm{~F}$ & Ovarian cancer & 8 & $\begin{array}{l}\text { Adnexectomy, colic omentum resection, iliac fossa and pelvic peritoneum } \\
\text { resection }\end{array}$ & 1 & SWT \\
\hline 19 & 67 & $\mathrm{~F}$ & Ovary cancer & 29 & $\begin{array}{l}\text { Ovariectomy, resection of pelvic peritoneum, colic omentum, and } \\
\text { diaphragmatic membrane }\end{array}$ & 3 & $9 \mathrm{mo}$ \\
\hline 20 & 64 & $\mathrm{~F}$ & $\begin{array}{l}\text { Malignant } \\
\text { peritoneum } \\
\text { mesothelioma }\end{array}$ & 30 & $\begin{array}{l}\text { Transverse colon resection, partial small intestine resection, colic } \\
\text { omentum and epigastric peritoneum resection }\end{array}$ & 3 & $30.5 \mathrm{mo}$ \\
\hline 21 & 60 & $\mathrm{~F}$ & $\begin{array}{l}\text { Pseudomyxoma } \\
\text { peritonei }\end{array}$ & 33 & $\begin{array}{l}\text { Hepatic region peritoneum, splenic region peritoneum, and pelvic } \\
\text { peritoneum resection }\end{array}$ & 3 & SWT \\
\hline
\end{tabular}

$C C R$ completeness of cryoreduction, SWT survival with tumor, SWOT survival without tumor, $P C I$ peritoneal carcinomatosis index

${ }^{\text {a }}$ Follow-up continued until August 1, 2008, either by outpatient clinic or by telephone

b A CCR score of 0 indicates no residual peritoneal disease after CRS; 1, $<2.5 \mathrm{~mm}$ of residual disease; 2 , residual tumor between $2.5 \mathrm{~mm}$ and $2.5 \mathrm{~cm}$; and $3,>2.5 \mathrm{~cm}$ of residual tumor or the presence of a sheet of unresectable tumor nodules

$73.3 \% .^{23}$ In a prospective study by Bijelic et al., among 70 patients with colorectal cancer undergoing combined treatment, 49 developed documented recurrence at median time for progression of 9 months, and most recurrent disease occurred inside the abdomen. ${ }^{24}$ One possible cause for such a high failure rate could be the marked differences in drug sensitivity between different PC types and between individuals with the same tumor types, as was found in a recent study of patient $\mathrm{PC}$ samples. ${ }^{27}$

In conclusion, CRS + HIPEC is a relatively safe treatment option in selected patients with PC that originates from gastrointestinal tract and gynecological malignancies, resulting in improved outcomes. There are still many problems about CRS + HIPEC, and a higher-level clinical 
trial is needed to provide more supportive evidence and to standardize the procedure. ${ }^{28-30}$ On the basis of these results, we have registered and started a phase II randomized clinical trial (NCT00454519; http://www.clinicaltrials.gov). We hope that this trial will help gain better evidence to support this procedure.

ACKNOWLEDGMENTS This work was supported by NewCentury Excellent Talents Supporting Program of the Ministry of Education of China (NCET-04-0669) and the Foundation for the Author of National Excellent Doctoral Dissertation of China (FANEDD-200464).

Open Access This article is distributed under the terms of the Creative Commons Attribution Noncommercial License which permits any noncommercial use, distribution, and reproduction in any medium, provided the original author(s) and source are credited.

\section{REFERENCES}

1. Blair SL, Chu DZ, Schwarz RE. Outcome of palliative operations for malignant bowel obstruction in patients with peritoneal carcinomatosis from nongynecological cancer. Ann Surg Oncol. 2001;8:632-7.

2. Fizazi K, Doubre H, Le Chevalier T, et al. Combination of raltitrexed and oxaliplatin is an active regimen in malignant mesothelioma: results of a phase II study. J Clin Oncol. 2003; 21:349-54.

3. Gómez Portilla A, Cendoya I, López de Tejada I, et al. Peritoneal carcinomatosis of colorectal origin. Current treatment. Review and update. Rev Esp Enferm Dig. 2005;97:716-37.

4. Yonemura Y, Bando E, Kawamura T, et al. Cytoreduction and intraperitoneal chemotherapy for carcinomatosis from gastric cancer. Cancer Treat Res. 2007;134:357-73.

5. Sugarbaker PH. Successful management of microscopic residual disease in large bowel cancer. Cancer Chemother Pharmacol. 1999;43:S15-25.

6. Stewart JH IV, Shen P, Levine EA. Intraperitoneal hyperthermic chemotherapy for peritoneal surface malignancy: current status and future directions. Ann Surg Oncol. 2005;12:765-77.

7. Sugarbak PH. Cytoreduction surgery and perioperative intraperitoneal chemotherapy as a curative approach to Pseudomyxoma peritonei syndrome. Eur J Surg Oncol. 2001;27:239-43.

8. Shen P, Levine EA, Hall J, et al. Factors predicting survival after intraperitoneal hyperthermic chemotherapy with mitomycin $\mathrm{c}$ after cytoreductive surgery for patients with peritoneal carcinomatosis. Arch Surg. 2003;138:26-33.

9. Sugarbaker PH. Cytoreductive surgery and intraperitoneal chemotherapy with peritoneal spread of cystadenocarcinoma. Eur $J$ Surg Suppl. 1991;561:75-82.

10. Piso P, Dahlke MH, Ghali N, et al. Multimodality treatment of peritoneal carcinomatosis from colorectal cancer: first results of a new German centre for peritoneal surface malignancies. Int $J$ Colorectal Dis. 2007;22:1295-300.

11. Yan TD. Peritoneal carcinomatosis of colorectal origin: standard of care. Ann Surg. 2006;244:632-3.

12. Bae JH, Lee JM, Ryu KS, et al. Treatment of ovarian cancer with paclitaxel- or carboplatin-based intraperitoneal hyperthermic chemotherapy during second surgery. Gyn Oncol. 2007;106:193-200.

13. Yonemura $\mathrm{Y}$, Ikeno $\mathrm{T}$, Shinbo $\mathrm{M}$, et al. Long-term results of peritonectomy on the patients with peritoneal carcinomatosis. Gan To Kagaku Ryoho. 2007;34:1926-30.
14. Verwaal VJ, van Ruth S, de Bree E, et al. Randomized trial of cytoreduction and hyperthermic intraperitoneal chemotherapy versus systemic chemotherapy and palliative surgery in patients with peritoneal carcinomatosis of colorectal cancer. J Clin Oncol. 2003;21:3737-43

15. Yan TD, Black D, Savady R, et al. Systemic review on the efficacy of cytoreductive surgery combined with perioperative intraperitoneal chemotherapy for peritoneal carcinomatosis from colorectal carcinoma. J Clin Oncol. 2006;24:4011-9.

16. Esquivel J, Sticca R, Sugarbaker P, et al. Cytoreductive surgery and hyperthermic intraperitoenal chemotherapy in the management of peritoneal surface malignancies of colonic origin: a consensus statement. Society of Surgical Oncology. Ann Surg Oncol. 2007;14:128-33.

17. Smeenk RM, Verwaal VJ, Zoetmulder FAN. Learning curve of combined modality treatment in peritoneal surface disease. $\mathrm{Br} \mathrm{J}$ Surg. 2007;94:1408-14.

18. Li PC, Chen LD, Zheng F, et al. Intraperitoneal chemotherapy with hydroxycamptothecin reduces peritoneal carcinomatosis: results of an experimental study. J Cancer Res Clin Oncol. 2008; 134:37-44.

19. Koppe MJ, Boerman OC, Oyen WJ, et al. Peritoneal carcinomatosis of colorectal origin: incidence and current treatment strategies. Ann Surg. 2006;243:212-22.

20. Scaringi S, Kianmanesh R, Sabate JM, et al. Advanced gastric cancer with or without peritoneal carcinomatosis treated with hyperthermic intraperitoneal-chemotherapy: a single Western center experience. Eur J Surg Oncol. 2008. doi:10.1016/j.ejso. 2007.12.003.

21. Yan TD, Zappa L, Edwards G, et al. Perioperative outcomes of cytoreductive surgery and perioperative intraperitoneal chemotherapy for non-appendiceal peritoneal carcinomatosis from a prospective database. J Surg Oncol. 2007;96:102-12.

22. Verwaal VJ, van Ruth S, Witkamp A, et al. Long-term survival of peritoneal carcinomatosis of colorectal origin. Ann Surg Oncol. 2005; 12:65-71.

23. Glehen O, Kwiatkowski F, Sugarbaker PH, et al. Cytoreductive surgery with perioperative intraperitoneal chemotherapy for the management of peritoneal carcinomatosis from colorectal cancer: a multi-institutional study. J Clin Oncol. 2004;22:3284-92.

24. Bijelic L, Yan TD, Sugarbaker PH. Failure analysis of recurrent disease following complete cytoreduction and perioperative intraperitoneal chemotherapy in patients with peritoneal carcinomatosis from colorectal cancer. Ann Surg Oncol. 2007; $14: 2281-8$.

25. Cavaliere F, Valle M, De Simone M, et al. 120 peritoneal carcinomatoses from colorectal cancer treated with peritonectomy and intra-abdominal chemohyperthermia: a SITILO multicentric study. In Vivo. 2006;20:747-50.

26. Glehen O, Cotte E, Schreiber V, et al. Intraperitoneal chemohyperthermia and attempted cytoreductive surgery in patients with peritoneal carcinomatosis of colorectal origin. Br J Surg. 2004; 91:747-54

27. Mahteme H, von Heideman A, Grundmark B, et al. Heterogeneous activity of cytotoxic drugs in patient samples of peritoneal carcinomatosis. Eur J Surg Oncol. 2008;34:547-52.

28. Al-Shammaa HA, Li Y, Yonemura Y. Current status and future strategies of cytoreductive surgery plus intraperitoneal hyperthermic chemotherapy for peritoneal carcinomatosis. World $J$ Gastroenterol. 2008;14:1159-66.

29. Markman M. Intraperitoneal hyperthermic chmotherapy as treatment of peritoneal carcinomatosis of colorectal cancer. $J$ Clin Oncol. 2004;22:1527.

30. Hildebrandt B, Rau B, Gellermann J, et al. Hyperthermic intraperitoneal chemotherapy in patients with peritoneal carcinosis. $J$ Clin Oncol. 2004;22:1527-9. 